\title{
Vertebral and non-vertebral low-traumatic fractures in patients with type 2 diabetes mellitus (T2DM).
}

Yalochkina T.O. , Belaya Z.E. , Rozhinskaya L.Y., Antsiferov M.B., Shestakova M.V., Dzeranova L.K., Melnichenko G.A.

Endocrinology Recearch Centre, Moscow, Russian Federation

\section{OBJECTIVES}

Recent evidence suggests that the skeleton might be another affected organ in patients with type 2 diabetes mellitus (T2DM). This study evaluates the prevalence of low-traumatic vertebral and non-vertebral fractures and their risk factors in subjects with T2DM.

\section{RESULTS}

200 (141 (70.5\% females) consecutive T2DM patients were enrolled The median of age (Q25-Q75) 66 (60-74 years), BMI 31 (27-36) $\mathrm{kg} / \mathrm{m} 2$, disease duration $8(4-14)$ years (neuropathy was diagnosed in 113 patients, retinopathy-94, nephropathy-8), HbA1c $7.4 \%$ (6.7-8.5). Fractures were reported in 68 (34\%) patients, in $26(13 \%)$ cases there were vertebral fractures and in $52(26 \%)$ low-traumatic nonvertebral fractures. In 10 cases multiple fractures both vertebral and/or non-vertebral were registered. The most frequent fractures were of low-extremities including 2 hip and 26 shin fractures; the upper-extremities were the next most frequent location including 3 humerus, 19 wrist and 4 ulna fractures. Subjects with any fractures were older $p=0.004$, but did not differ in disease duration $p=0.196$, $\mathrm{HbA} 1 \mathrm{c} p=0.99$, or calcium intake $p=0.62$. It seems that subjects with retinopathy fractured more $-42.9 \%$ as compared to patients without retinopathy $-27.6 \% p=0.001$, no difference in any other complications were found. Subjects with fracture had lower grip strength in both hands $30.0(24.6-39.5)$ vs $26.5(22.7-31.5) \mathrm{dAN} p=0.019$ right hand; $27.7(22.1-37.5)$ vs $25.0(20.0-31.8) \mathrm{dAN}$ left hand $p=0.013$

\section{Complications of T2DM ( number of enrolled patients)}

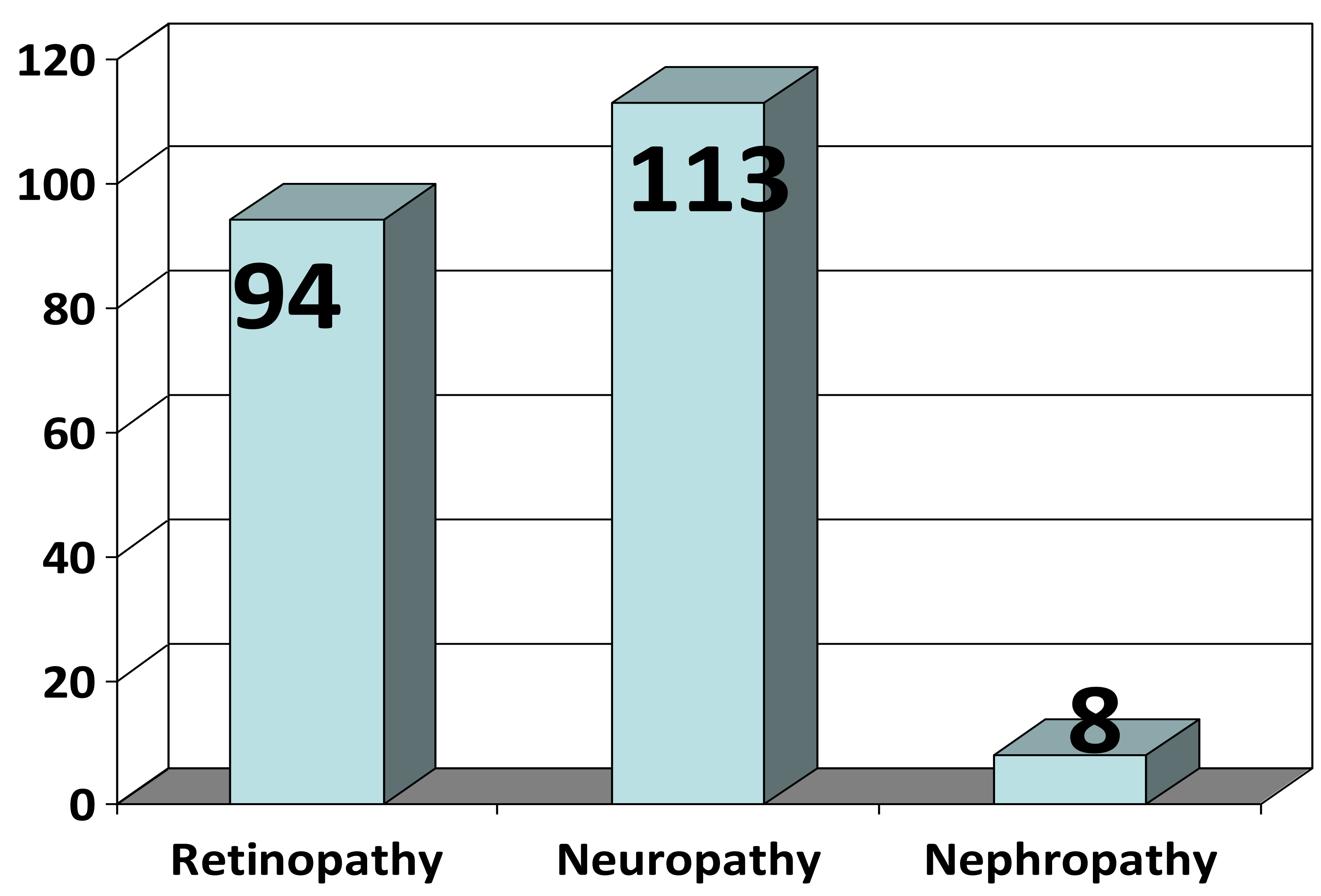

\section{References}

1.Ström O, Borgström F, Kanis J, et al. Osteoporosis: burden, health care provision and opportunities in the EU: a report prepared in collaboration with the International Osteoporosis Foundation (IOF) and the European Federation of Pharmaceutical Industry Associations. Arch Osteoporos 2011;6:59-155

2. Bonds DE, Larson JC, Schwartz AV, et al. Risk of fracture in women with type 2 diabetes: the Women's Health Initiative Observational Study. J Clin Endocrinol Metab. 2006;91(9):34043410.

3. P. Vestergaard, Discrepancies in bone mineral density and fracture risk in patients with type 1 and type 2 diabetes - a meta-analysis, Osteoporos. Int 18 (2007) 427-444

4. Janghorbani M, Feskanich D, WilltW WC, Hu F. Prospective study of diabetes and risk of hip fracture: the Nurses' Health Study. Diabetes Care 2006:29(7):1573-8.

fracture: the NJ 5. Mellon III LJ, Leibson CL, Achenbach SJ, Themeau TM, Khosla S. Fracture isk in type diabetes: update of a population-based study. J Bone Miner Res 2008;23(8): 1334-42. 6.Janghorbani M, Van Dam RM, Willett WC, Hu FB. Systematic review of type 1 and type 2 diabetes mellitus and risk of fracture. Am J Epidemiol 2007;166(5):495-505.

7.de Liefde II, van der Klift M, de Laet CE, van Daele PL, Hofman A, Pols HA. Bone mineral density and fracture risk in type-2 diabetes mellitus: the Rotterdam Study. Osteoporos Int 2005;16(12):1713-20.
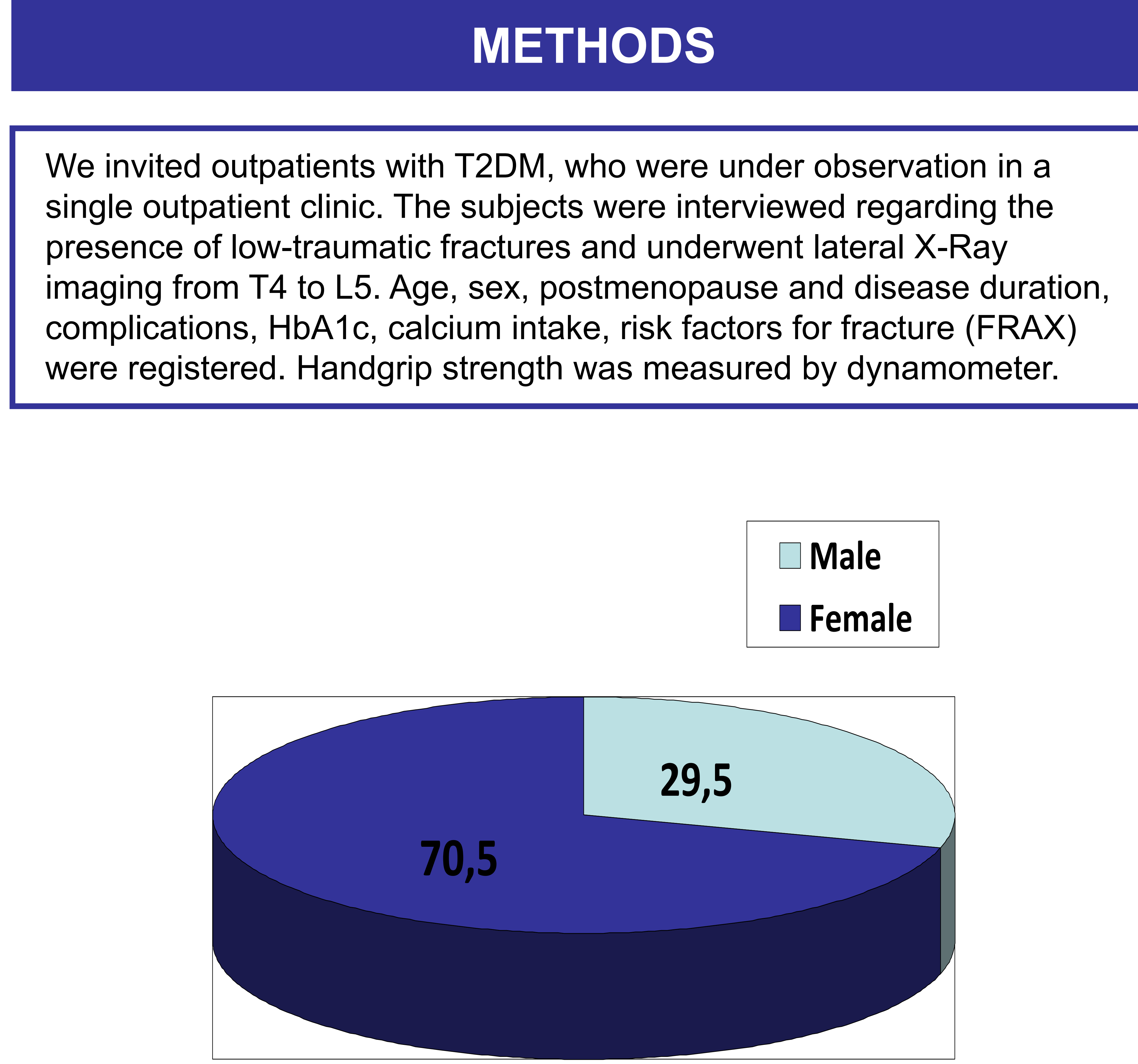

\section{CONCLUSIONS}

Patients with T2DM have high prevalence of low-traumatic fractures (34\%) mostly of low-extremities, which might be related to both ageing and general frailty as well as diabetes complications such as retinopathy.

Difference in complication of T2DM ( $\%$ of fractures)

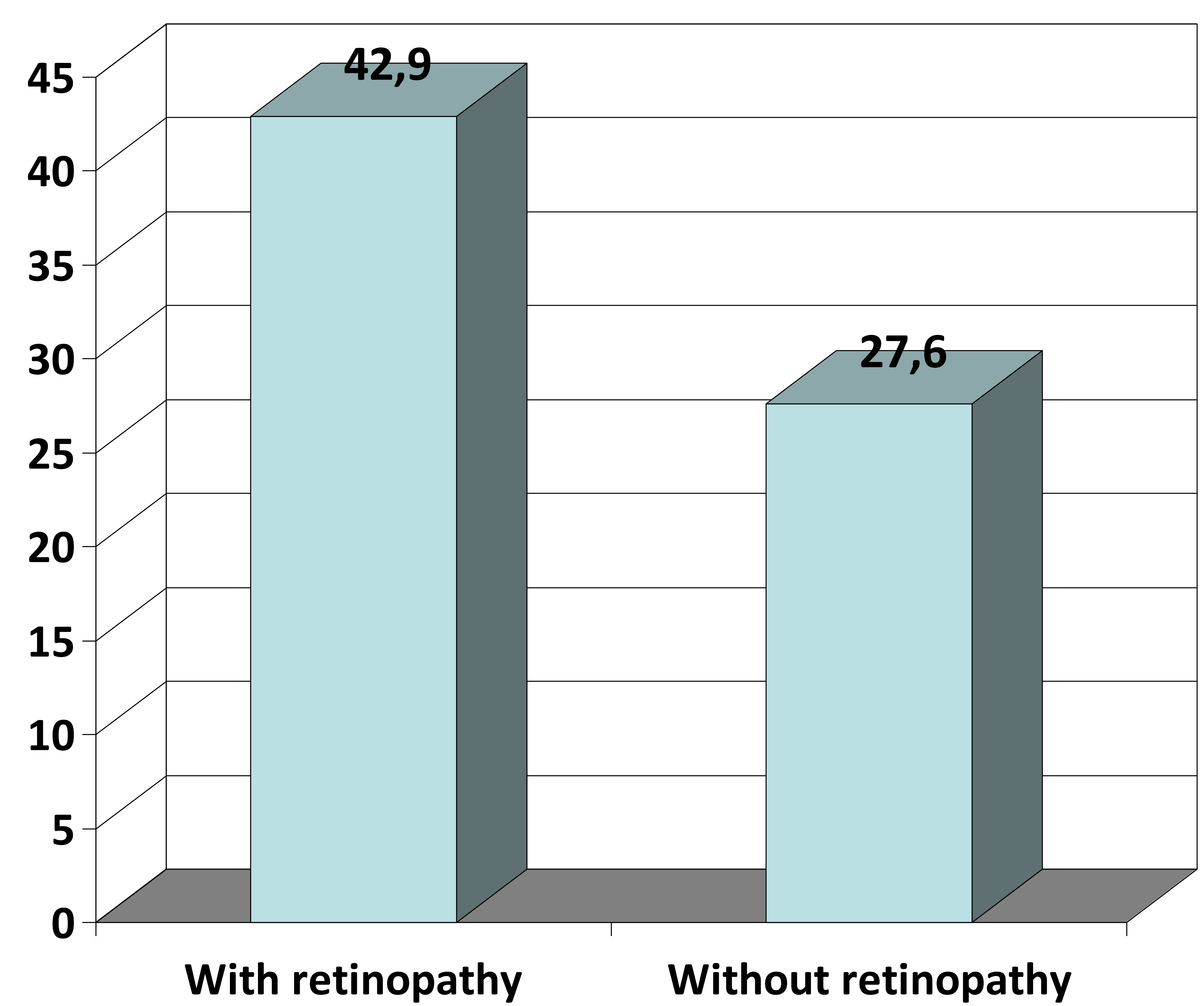

Without retinopathy 